\title{
Exopolysaccharide Production by Pseudomonas NCIB11264 Grown in Continuous Culture
}

\author{
By A. G. WILLIAMS* AND J. W. T. WIMPENNY \\ Department of Microbiology, University College, Cardiff CF2 ITA
}

(Received 22 June 1977; revised 24 August 1977)

\begin{abstract}
Exopolysaccharide formation by Pseudomonas NCIBII264 in a single-stage continuous culture was maximal under nitrogen limitation with excess carbohydrate substrate at $30 \pm \mathrm{I}{ }^{\circ} \mathrm{C}$ and $\mathrm{pH} 7 \cdot 0 \pm 0 \cdot \mathrm{I}$. Polysaccharide production was not enhanced by phosphate limitation but was dependent on the dilution rate. Steady states were maintained for up to $500 \mathrm{~h}$ without deterioration of the culture or the development of mutant strains. The efficiency of conversion of the glucose substrate utilized into exopolysaccharide by the chemostat cultures was as high as $73 \%$.
\end{abstract}

\section{INTRODUCTION}

Pseudomonas NCIBII264 forms an extracellular acylated slime polysaccharide in which the monosaccharides glucose, galactose, rhamnose and mannose have been detected (Williams, Wimpenny \& Lawson, 1973). Preliminary batch fermentation studies indicated that the exopolysaccharide is synthesized over a wide range of cultural conditions, although the amount of polymer produced is influenced by medium composition and environmental factors (Williams \& Wimpenny, 1977). The effect of growth conditions on microbial exopolysaccharide production has, in the past, been mainly determined by plate and smallscale batch culture techniques, whilst the obvious potential of continuous culture both as a research and production tool has remained largely unexploited. However, the production of the exopolysaccharide xanthan gum by Xanthomonas campestris has been studied not only in batch cultures at both the laboratory (Lilly, Wilson \& Leach, 1958) and pilot plant level (Rogovin, Anderson \& Cadmus, 196I) but also in single-stage continuous (chemostat) fermentations (Lindblom \& Patton, 1967; Rogovin, 1969). The kinetics of the xanthan biopolymer fermentation, determined in batch culture experiments (Moraine \& Rogovin, 1966, 1973), were shown to be applicable to continuous fermentations in which the xanthan production rate was a function of the dilution rate and $\mathrm{pH}$ (Silman \& Rogovin, 1970, 1972).

In this paper, we report the effects of growth parameters on exopolysaccharide formation by Pseudomonas NCIBII264 in a single-stage continuous fermenter. A preliminary report of some of these findings has already been published (Williams \& Wimpenny, 1976).

\section{METHODS}

Maintenance of culture and preparation of inoculum. Pseudomonas NCIBI I 264 was maintained on nutrient agar slopes supplemented with glucose $(2 \%, w / v)$ and subcultured at monthly intervals with overnight incubation at $30^{\circ} \mathrm{C}$ followed by storage at $4{ }^{\circ} \mathrm{C}$. Inocula $(200 \mathrm{ml})$ were prepared from a single slant in a chemically defined medium containing glucose $(2 \%, \mathrm{w} / \mathrm{v})$ as carbon source and the following components ( $\mathrm{mg} \mathrm{l}^{-1}$ ): $\mathrm{NH}_{4} \mathrm{Cl}(2660), \mathrm{KH}_{2} \mathrm{PO}_{4}$ (5440), $\mathrm{MgSO}_{4} \cdot 7 \mathrm{H}_{2} \mathrm{O}(60), \mathrm{MnCl}_{2} \cdot 4 \mathrm{H}_{2} \mathrm{O}$ (6), $\mathrm{FeSO}_{4} \cdot 7 \mathrm{H}_{2} \mathrm{O}(2 \cdot 4)$, and

* Present address: Department of Biochemistry, Hannah Research Institute, Ayr, Scotland KA6 5 HL. 
$\mathrm{CaCl}_{2}, 2 \mathrm{H}_{2} \mathrm{O}(0 \cdot 6)$, buffered to $\mathrm{pH} 7 \cdot 0$. A portion $(20 \mathrm{ml})$ of the overnight culture (gyratory incubation, $\mathrm{I} 20 \mathrm{rev} \cdot \mathrm{min}^{-1}, 30^{\circ} \mathrm{C}$ ) was inoculated into the chemostat containing $500 \mathrm{ml}$ medium. After inoculation the culture was established by batch growth for $24 \mathrm{~h}$ before the addition of medium was commenced. Steady states were allowed to establish for at least $72 \mathrm{~h}$ and all samples were subsequently removed directly from the fermentation vessel.

Continuous fermentation. The I I continuous culture system used was based on the 'Porton-type' chemostat (Evans, Herbert \& Tempest, 1970), and included facilities for the control of $\mathrm{pH}$, temperature, gas flow rates, impeller speed and foaming (Williams, 1974). The fermentation vessel, medium reservoirs $(3 \times 201)$ and all other in-line vessels (containing acid/alkali, antifoam, glucose component of the defined medium) were fully assembled prior to autoclaving $\left(12 I^{\circ} \mathrm{C}, 60 \mathrm{~min}\right)$. The medium was pumped into the growth vessel with an LKB Varioperpex 12000 peristaltic pump, and the effluent was discharged continuously through an overflow weir, set at the $550 \mathrm{ml}$ level, into a sterile product collection unit. As the exopolysaccharide produced prevented foaming, antifoam was not added.

Determination of the oxygen transfer characteristics of the fermentation vessel. In the presence of catalytic amounts of copper ions, sulphite is rapidly oxidized to sulphate by dissolved oxygen, at a rate equal to that of oxygen solution (i.e. transfer). The iodometric method used was that of Cooper, Fernstrom \& Miller (1944). The completely assembled nitrogen-sparged fermentation vessel was filled to its working capacity with $0.25 \mathrm{M}$-sodium sulphite, and after $10 \mathrm{~min}$ equilibration to $30^{\circ} \mathrm{C}$ the gas flow rates were adjusted and the copper sulphate catalyst (o. I $\mathrm{mg}$ ) was added. Sulphite samples ( $\mathrm{r} \mathrm{ml}$ ) were removed at intervals and transferred to a titration flask containing $0.1 \mathrm{M}$-iodine solution $(25 \mathrm{ml})$ and $2 \mathrm{M}-\mathrm{HCl}(5 \mathrm{ml})$. The residual sulphite was oxidized by the iodine and the unused iodine was titrated against O.I M-sodium thiosulphate with a starch indicator.

Analytical methods. The ammonia-nitrogen and phosphate contents of the growth medium and effluent liquor were estimated colorimetrically using the methods described by Solorzano (1969) and Fiske \& Subbarow (1925) respectively; the glucose concentration was measured enzymically with glucose oxidase (Sigma). The total cell protein was determined in washed suspensions by the method of Lowry et al. (I95I), after cell lysis with an equal volume of $\mathrm{I} \mathrm{M}-\mathrm{NaOH}\left(5 \mathrm{~min}, \mathrm{IOO}^{\circ} \mathrm{C}\right)$. Total cell carbohydrate was determined by the phenol- $\mathrm{H}_{2} \mathrm{SO}_{4}$ reaction (Dubois et al., 1956) with a glucose standard. Exopolysaccharide in cell-free culture supernatants was estimated by two of the following methods described by Williams \& Wimpenny (1977): (i) colorimetrically, using the phenol- $\mathrm{H}_{2} \mathrm{SO}_{4}$ reaction; (ii) by viscometry, with a modified ZimmCrothers viscometer $\left(55 \mathrm{~mA}, 25 \pm 0.2{ }^{\circ} \mathrm{C}\right)$; (iii) gravimetrically, after precipitation with propan-2-ol.

The recovery and preparation of polysaccharide samples for analysis and the techniques used in the identification of the monosaccharide components of the exopolymer and for the determination of hexose, deoxyhexose, acetate and pyruvic acid have been described (Williams \& Wimpenny, 1977).

Viscosity measurement. Culture viscosity was measured at $25 \pm 0.2{ }^{\circ} \mathrm{C}$ with an applied rate of shear of $437 \mathrm{~s}^{-1}$ using a Haake viscometer (Haake Instruments, Berlin) fitted with the NV rotary assembly (Williams, 1974). The exopolysaccharide exhibits pseudoplastic, but not thixotropic, rheological characteristics (Williams, 1974) and thus the apparent viscosity figures quoted for the fermentation liquor are shear-rate dependent.

\section{RESULTS}

\section{Oxygen transfer characteristics of the system}

The oxygen transfer characteristics of the fermenter were determined so that impeller speed and gas flow rates could be selected to ensure efficient aeration of the culture in the presence of exopolysaccharide. The effect of increasing impeller speed on oxygen solution at constant gas flow rate and temperature, and the uptake of oxygen from oxygen/nitrogen mixtures at constant impeller speed and temperature were examined. In both experiments, the total volume of gas passing through the fermenter was $500 \mathrm{ml} \mathrm{min}^{-1}$ and the temperature was $30 \pm \mathrm{I}{ }^{\circ} \mathrm{C}$. The oxygen uptake rate increased linearly with impeller speed from 500 to I $200 \mathrm{rev}$. $\min ^{-1}$ (Fig. I); it was also directly proportional to the partial pressure of oxygen in the inflowing gas mixture of constant volume and flow rate at a constant impeller speed (Fig. I).

At a constant motor output the impeller speed decreased with increasing culture viscosity and the linear relationship between oxygen uptake rate and impeller speed was restricted to a much narrower range of impeller speeds $\left(750\right.$ to $\left.900 \mathrm{rev} . \mathrm{min}^{-1}\right)$ in the presence of low levels of exopolysaccharide $\left(2.5 \mathrm{mg} \mathrm{ml}^{-1}\right)$ (Fig. I). At impeller speeds of 700 to Iooo rev. $\mathrm{min}^{-1}$ the reduction in oxygen uptake rate was $10 \%$ at a polysaccharide concentration of 


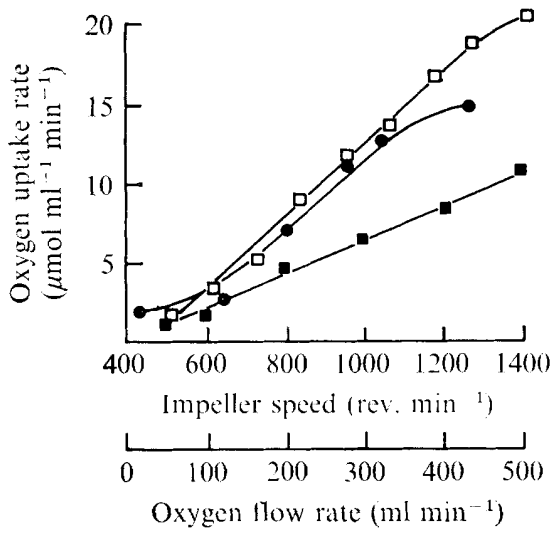

Fig. I. Oxygen uptake rates at various impeller speeds in the absence ( $\square$ ) or presence (O) of exopolysaccharide $\left(2.5 \mathrm{mg} \mathrm{ml}^{-1}\right)$ under otherwise identical conditions (gas flow rate $500 \mathrm{ml} \mathrm{min}^{-1}$, $30^{\circ} \mathrm{C}$ ). Also shown is the oxygen uptake-flow rate relationship ( $\square$ ) (impeller speed $850 \mathrm{rev} . \mathrm{min}^{-1}$, $30{ }^{\circ} \mathrm{C}$ ): the total gas flow was maintained at $500 \mathrm{ml} \mathrm{min}^{-1}$ in which $\mathrm{O}_{2}$ was varied from 50 to $500 \mathrm{ml} \mathrm{min}^{-1}$.

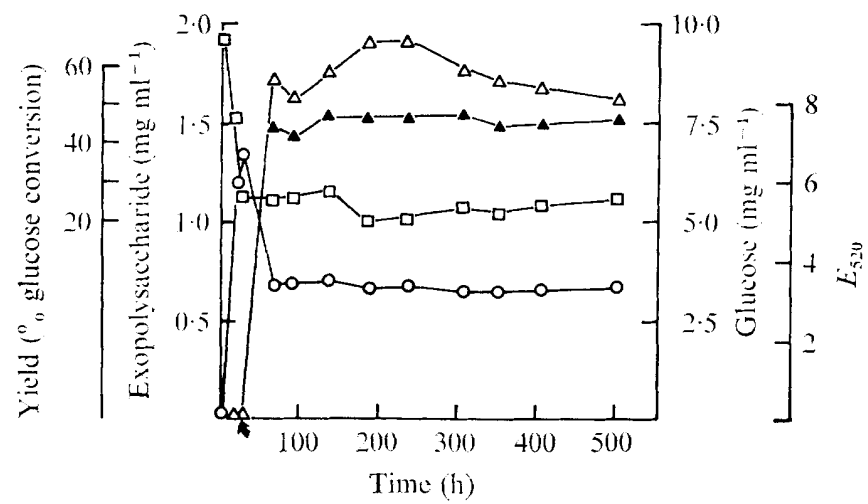

Fig. 2. Steady-state exopolysaccharide production by Pseudomonas NCIBI 264 showing variations in $E_{520}(O)$, exopolysaccharide concentration $(\triangle)$, glucose conversion efficiency $(\boldsymbol{\Delta})$ and glucose concentration ( $\square$ ). The culture was established for $24 \mathrm{~h}$ prior to the metered addition of medium started at the time indicated by the arrow.

$2.5 \mathrm{mg} \mathrm{ml}^{-1}$, but became more pronounced as the impeller speed increased $(20 \%$ at I 270 rev. $\left.\min ^{-1}\right)$. Thus, in the following series of experiments, the rate of aeration was main-

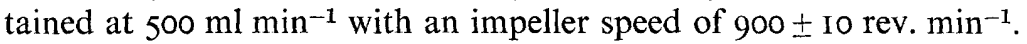

\section{Exopolysaccharide production in continuous culture}

Steady-state exopolysaccharide formation was examined under conditions of nitrogen limitation at $\mathrm{pH} 7 \pm 0 . \mathrm{I}$ and $30 \pm \mathrm{I}{ }^{\circ} \mathrm{C}$, at a dilution rate of $0.08 \mathrm{~h}^{-1}$ for $500 \mathrm{~h}$ (Fig. 2). Steady-state values for exopolysaccharide levels and the efficiency of conversion of the glucose utilized into the exopolymer remained constant. There was no evidence of cultural deterioration or the development of mutant strains.

Polysaccharide samples analysed were of constant composition (Table I) and solutions of representative polymer samples ( $100 \mu \mathrm{g} \mathrm{ml}^{-1}$ ) had similar relative viscosities ( $1 \cdot 70 \pm 0.05$ ) when measured at $25^{\circ} \mathrm{C}$ using a modified Zimm-Crothers rotating cylinder viscometer (Williams, 1969) with an applied current of $55 \mathrm{~mA}$. 


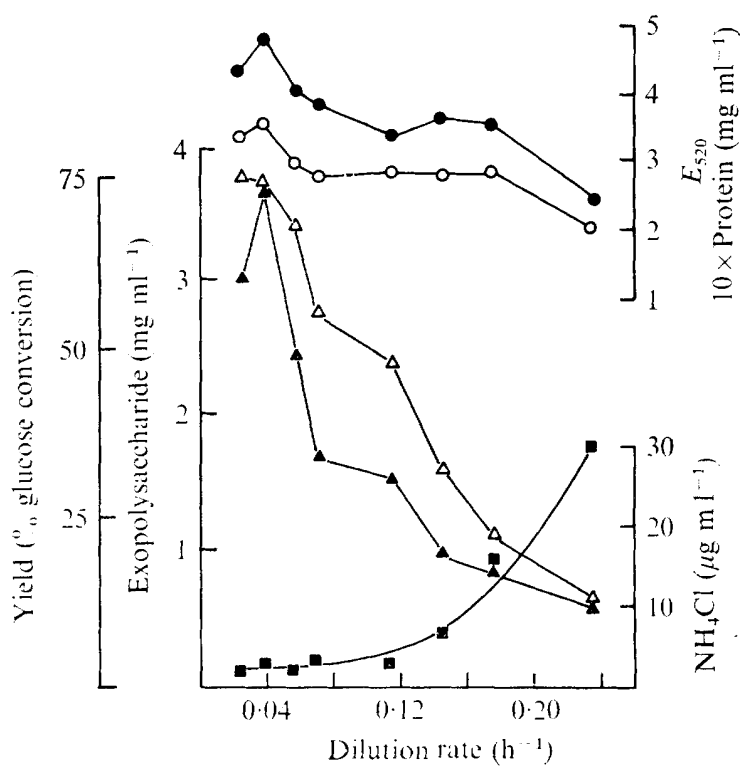

Fig. 3. Effect of dilution rate on steady-state exopolysaccharide production $(\Delta)$, glucose conversion efficiency $(\boldsymbol{\Lambda})$, total cell population, estimated as $E_{520}(\bigcirc)$ and culture protein $(\bullet)$, and concentration of $\mathrm{NH}_{4} \mathrm{Cl}$ as limiting nutrient $(\boldsymbol{\square})$.

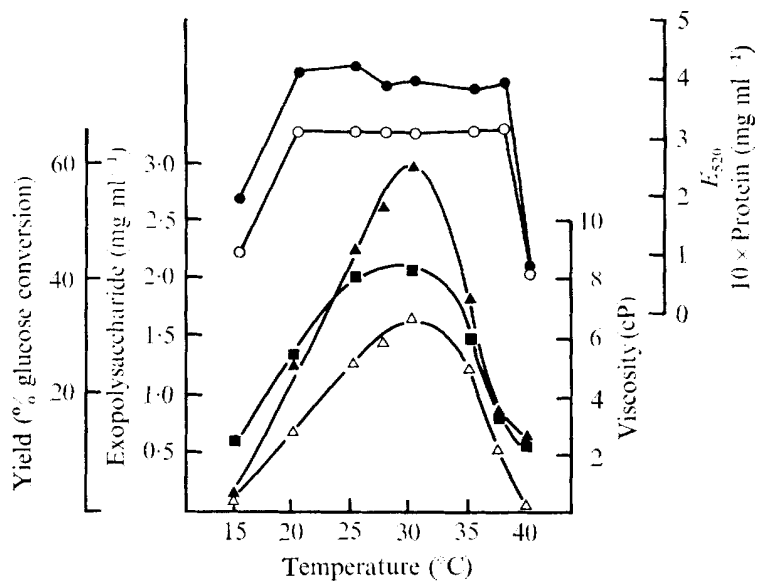

Fig. 4. Effect of temperature on steady-state exopolysaccharide production $(\triangle)$, glucose conversion efficiency $(\Delta), E_{520}(\bigcirc)$, total culture protein $(O)$ and culture viscosity at $25{ }^{\circ} \mathrm{C}$ (rate of shear $\left.437 \mathrm{~s}^{-1}\right)(\mathbf{E})$.

\section{Effect of growth conditions on exopolysaccharide formation}

Dilution rate. The effect of dilution rate $\left(D=0.023\right.$ to $\left.0.23 \mathrm{~h}^{-1}\right)$ on exopolysaccharide production was determined in nitrogen-limited cultures at $30{ }^{\circ} \mathrm{C}$ and $\mathrm{pH} 7$. The amount of polysaccharide produced was related to the dilution rate and decreased with increasing dilution rate, although the steady-state cell population remained relatively constant over the whole range of dilution rates (Fig. 3). The maximum yield of polysaccharide, from the glucose utilized, was $73 \%$. The composition of the exopolysaccharide produced at various dilution rates in the chemostat was not significantly different from that produced in batch culture (Table I). 
Table I. Exopolysaccharide formation by cells grown under various conditions in a chemostat

Polysaccharide samples were prepared and analysed as described by Williams \& Wimpenny (I977). The deoxyhexose content was less than $10 \%$ in all samples, after correction for the hexose interference in the assay system.

\begin{tabular}{|c|c|c|c|c|c|c|c|c|c|c|}
\hline & & & Stea & $\begin{array}{l}\text { tate co } \\
\text { polysa }\end{array}$ & $\begin{array}{l}\text { nditions un } \\
\text { ccharide for }\end{array}$ & $\begin{array}{l}\text { der which } \\
\text { rmed }\end{array}$ & & & Composit & n \\
\hline Experit & ental & & & Temp. & $\begin{array}{l}\text { Glucose } \\
\text { concn }\end{array}$ & $\begin{array}{l}\mathrm{NH}_{4} \mathrm{Cl} \\
\text { concn }\end{array}$ & $\mathrm{KH}_{0} \mathrm{PO}_{4}$ & U & $(\%, w / v$ & \\
\hline vario & & $D\left(\mathrm{~h}^{-1}\right)$ & $\mathrm{pH}$ & $\left({ }^{\circ} \mathrm{C}\right)$ & $\left(\mathrm{mg} \mathrm{ml}^{-1}\right)$ & $\left(\mu \mathrm{g} \mathrm{ml}^{-1}\right)$ & $\left(\mathrm{mg} \mathrm{1}^{-1}\right)$ & Hexose & Acetate & yruvate \\
\hline Dilutic & & 0.023 & $7 \cdot 0$ & $30 \cdot 0$ & I $3 \cdot 8$ & $\mathbf{I} \cdot \mathbf{I}$ & ND & $74 \cdot 1$ & $3 \cdot 6$ & $8 \cdot 2$ \\
\hline rate ( & & 0.038 & & & 14.9 & $2 \cdot 7$ & & $71 \cdot 6$ & 3.5 & 6.9 \\
\hline & & 0.057 & & & 16.4 & $I \cdot 9$ & & $73 \cdot 8$ & $3 \cdot 6$ & $7 \cdot 0$ \\
\hline & & 0.176 & & & 19.8 & $15^{\circ} 0$ & & $72 \cdot 3$ & 3.9 & $7 \cdot 3$ \\
\hline $\mathrm{pH}$ & & 0.08 & $6 \cdot 4$ & $30 \cdot 0$ & I 3.9 & 0.4 & ND & $73 \cdot 1$ & $3 \cdot 5$ & $5 \cdot 9$ \\
\hline & & & $7 \cdot 0$ & & 17.0 & 0.3 & & $69 \cdot 0$ & $3 \cdot 8$ & $6 \cdot 1$ \\
\hline & & & $8 \cdot 0$ & & 17.0 & 0.3 & & $73 \cdot 2$ & 3.6 & $6 \cdot I$ \\
\hline & & & $8 \cdot 7$ & & $16 \cdot 7$ & 0.2 & & $7 \mathrm{I} \cdot 9$ & $3 \cdot 5$ & $5 \cdot 7$ \\
\hline Tempe & ature & 0.08 & $7 \cdot 0$ & $27 \cdot 5$ & I $5 \cdot 8$ & $6 \cdot 4$ & ND & $70 \cdot 0$ & $3 \cdot 8$ & $5 \cdot 8$ \\
\hline & & & & 30.0 & I 5.8 & 0.2 & & $68 \cdot 5$ & $3 \cdot 8$ & $5 \cdot 7$ \\
\hline & & & & $35^{\circ} 0$ & I 5.3 & $I \cdot I$ & & 66.0 & 3.9 & $5 \cdot 2$ \\
\hline & & & & $37 \cdot 5$ & I 5.5 & 0.2 & & $70 \cdot 5$ & $3 \cdot 7$ & $5 \cdot 8$ \\
\hline $\mathrm{NH}_{4} \mathrm{Cl}$ & & 0.08 & $7 \cdot 0$ & $30 \cdot 0$ & $16 \cdot 7$ & 0.4 & ND & $71 \cdot 2$ & $3 \cdot 8$ & $6 \cdot 4$ \\
\hline input & oncn & & & & $15 \cdot 4$ & I $\cdot 7$ & & $7 I \cdot 6$ & $3 \cdot 5$ & $8 \cdot 5$ \\
\hline & & & & & 10.5 & $22 \cdot 5$ & & $69 \cdot 8$ & $3 \cdot 6$ & $6 \cdot 3$ \\
\hline & & & & & $8 \cdot 9$ & 796 & & $7 I \cdot I$ & $3 \cdot 5$ & $6 \cdot 1$ \\
\hline Glucos & & $O \cdot I$ & $7 \cdot 0$ & $30 \cdot 0$ & 0.13 & $6 \cdot 4$ & ND & $71 \cdot 0$ & $3 \cdot 5$ & $5 \cdot 6$ \\
\hline input & oncn & & & & 0.78 & $1 \cdot 3$ & & $79 \cdot 0$ & 3.4 & $6 \cdot 6$ \\
\hline & & & & & $5 \cdot 7$ & $1 \cdot 6$ & & $77 \cdot 6$ & $3 \cdot 8$ & $5 \cdot 7$ \\
\hline & & & & & $16 \cdot 1$ & 0.4 & & $75 \cdot 4$ & 3.6 & $9 \cdot 3$ \\
\hline & & & & & $42 \cdot 4$ & $O \cdot I$ & & $69 \cdot 4$ & 3.5 & $5 \cdot 3$ \\
\hline & & & & & $2 \cdot 2$ & I 45 & & $72 \cdot 6$ & 4.0 & $5 \cdot 5$ \\
\hline Phosph & & 0.14 & $7 \cdot 0$ & $30 \cdot 0$ & $14 \cdot 3$ & $69 \cdot 5$ & 0.01 & $68 \cdot 9$ & $3 \cdot 9$ & $5 \cdot 5$ \\
\hline input & onen & & & & I I 8 & $1 \cdot 5$ & 106 & $73 \cdot 4$ & $3 \cdot 2$ & $6 \cdot 3$ \\
\hline & & & & & I 2.9 & $2 \cdot 6$ & 490 & $73 \cdot 8$ & $3 \cdot 2$ & $6 \cdot 7$ \\
\hline & & & & & $I I \cdot 2$ & 0.64 & 4030 & 67.0 & $3 \cdot 2$ & $8 \cdot 4$ \\
\hline Time* & & 0.08 & $7 \cdot 0$ & 30.0 & $5 \cdot 5$ & $3 \cdot 2$ & ND & $72 \cdot 7$ & 3.8 & $7 \cdot 8$ \\
\hline (h) & 90 & & & & 5.5 & $7 \cdot 7$ & & $70 \cdot 2$ & $3 \cdot 7$ & 6.0 \\
\hline & I36 & & & & $5 \cdot 7$ & $4 \cdot 3$ & & $68 \cdot 5$ & $3 \cdot 8$ & $7 \cdot 0$ \\
\hline & I 84 & & & & $4 \cdot 9$ & 0.8 & & $70 \cdot 2$ & $3 \cdot 8$ & $9 \cdot 3$ \\
\hline & 233 & & & & 4.9 & 0.8 & & $67 \cdot 1$ & $4 \cdot 0$ & $6 \cdot x$ \\
\hline & 304 & & & & $5 \cdot 3$ & 0.8 & & $69 \cdot 4$ & $3 \cdot 8$ & $4 \cdot 7$ \\
\hline & 352 & & & & $5^{\cdot I}$ & $\mathrm{I} \cdot \mathrm{I}$ & & $67 \cdot r$ & 4.0 & $6 \cdot 4$ \\
\hline & 405 & & & & $5 \cdot 3$ & 0.7 & & 67.0 & 3.6 & $8 \cdot I$ \\
\hline
\end{tabular}

ND, Not determined.

* Time after inoculation, see Fig. 2.

Temperature. To minimize problems created by high viscosities, a dilution rate of $0.08 \mathrm{~h}^{-1}$ was selected and the $\mathrm{pH}$ was maintained at 7 . Under nitrogen limitation, growth and polysaccharide production were considerably reduced at $15{ }^{\circ} \mathrm{C}$ and $40{ }^{\circ} \mathrm{C}$, whilst the optimum temperature for polysaccharide formation was $30^{\circ} \mathrm{C}$ with a maximum glucose conversion of $59.6 \%$ (Fig. 4). The efficiency of glucose conversion decreased markedly on either side of the optimum $\left(45 \%\right.$ at $25{ }^{\circ} \mathrm{C}$ and $36.8 \%$ at $\left.35{ }^{\circ} \mathrm{C}\right)$ although the steady-state cell population remained constant over a wide temperature range $\left(20\right.$ to $37 \cdot 5{ }^{\circ} \mathrm{C}$ ).

$p H$. The effect of $\mathrm{pH}$ on steady-state exopolysaccharide production was examined with nitrogen-limited cultures at $30{ }^{\circ} \mathrm{C}\left(D=0.08 \mathrm{~h}^{-1}\right)$. Maximum polymer levels were obtained at $\mathrm{pH} 6.5$ to 8 with a definite optimum at $\mathrm{pH} 7$. Below $\mathrm{pH} 6.5$ both the cell population and 


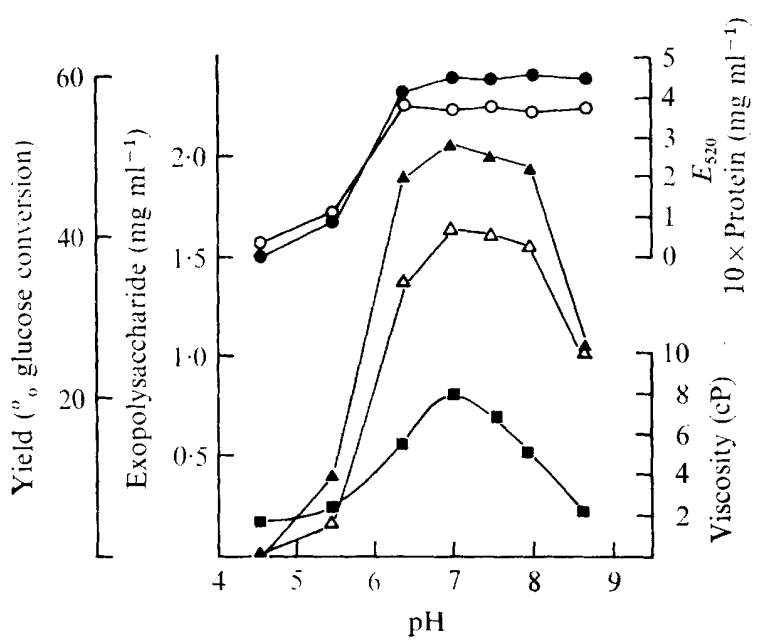

Fig. 5. Effect of $\mathrm{pH}$ on steady-state exopolysaccharide production $(\triangle)$, glucose conversion efficiency $(\boldsymbol{\Delta}), E_{520}(O)$, total culture protein $(\mathbf{O})$ and culture viscosity $(\boldsymbol{\square})$.

polysaccharide production were reduced (Fig. 5); increasing the $\mathrm{pH}$ to 8.7 also resulted in a reduction in the polysaccharide level $(42 \%)$ but not in the total cell population. The conversion of glucose into exopolysaccharide reached a maximum of $5 \mathrm{I} \cdot 6 \%$ at $\mathrm{pH} 7$ and fell only slightly to $48.5 \%$ at $\mathrm{pH} 8$. Under the fermentation conditions used, the $\mathrm{pH}$ fell to, and remained constant at, $\mathrm{pH} 6.7$ in the absence of $\mathrm{pH}$ control. The polysaccharide varied little in overall composition regardless of environmental $\mathrm{pH}$ (Table $\mathrm{I}$ ).

\section{Effect of medium composition on steady-state exopolysaccharide formation}

The effects of nutrient levels on exopolysaccharide production in continuous culture were examined with controlled $\mathrm{pH}(7 \cdot 0)$, temperature $\left(30^{\circ} \mathrm{C}\right)$ and aeration.

Nitrogen. Polysaccharide production increased with increasing nitrogen input to a maximum at $\mathrm{I} \cdot 25 \mathrm{mg} \mathrm{NH}_{4} \mathrm{Cl} \mathrm{ml}^{-1}$ but subsequently decreased as the nitrogen levels became non-limiting (indicated by the increasing $\mathrm{NH}_{4} \mathrm{Cl}$ content of the effluent). The steady-state cell population increased with $\mathrm{NH}_{4} \mathrm{Cl}$ input (Fig. 6) but, as in batch culture, was decreased at concentrations in excess of $2 \mathrm{mg} \mathrm{NH}_{4} \mathrm{Cl} \mathrm{ml}^{-1}$. The observed pattern suggested that at higher input levels factors other than the nitrogen content were growth limiting. Culture viscosity and encapsulation have been implicated in restricted nutrient transport into the cell with resultant growth limitation (Tanzer, Wood \& Krichevsky, 1969; Moraine \& Rogovin, 1973).

The formation of a green-yellow, extracellular, water-soluble pigment increased as the nitrogen:carbon ratio in the medium increased. The composition of the polysaccharide did not alter (Table I).

Glucose. Increasing the glucose input concentration of the defined medium $(0.5 \mathrm{mg}$ $\mathrm{NH}_{4} \mathrm{Cl} \mathrm{ml}^{-1}$ ) from 3.8 to $44.9 \mathrm{mg} \mathrm{ml}^{-1}$ had little effect on the steady-state polysaccharide production and glucose conversion efficiency of nitrogen-limited chemostat grown cells $\left(D=0 . \mathrm{I} \mathrm{h}^{-1}\right)$ (Fig. 7). Under glucose limitation $\left(<0.92 \mathrm{mg} \mathrm{ml}^{-1}\right)$ exopolymer could not be detected in cell-free culture supernatants by propan-2-ol precipitation and the total cell protein:total cell carbohydrate ratio was increased $(2.72$ and 0.95 at glucose inputs 0 f 0.92 and $30.5 \mathrm{mg} \mathrm{ml}^{-1}$, respectively). At higher nitrogen input levels $\left(1.6 \mathrm{mg} \mathrm{NH}_{4} \mathrm{Cl} \mathrm{ml}^{-1}\right)$ increasing the glucose concentration from $\mathrm{I} \cdot 2$ to $3 \mathrm{mg} \mathrm{ml}^{-1}$ did not remove the imposed limitation. Polysaccharide was formed, with low glucose conversion efficiency due to the associated increased cell population, at glucose input concentrations above $6 \mathrm{mg} \mathrm{ml}^{-1}$. 


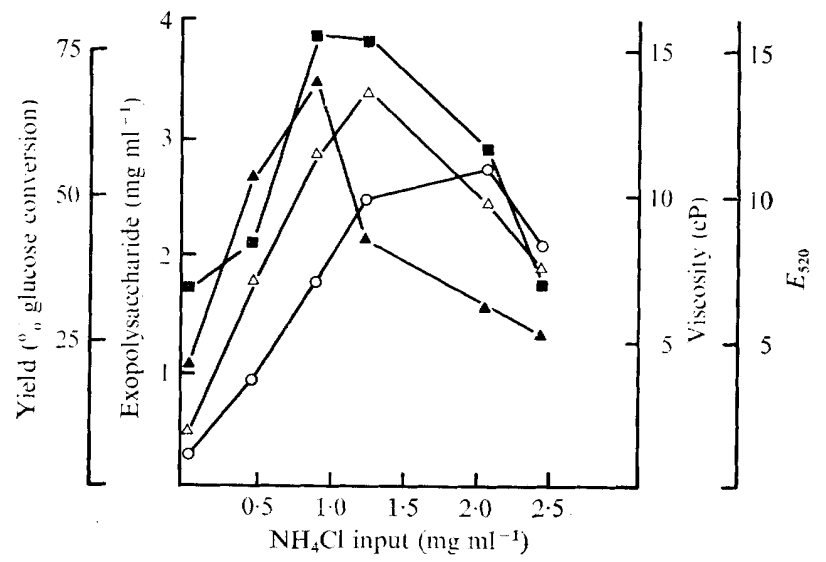

Fig. 6. Effect of the $\mathrm{NH}_{4} \mathrm{Cl}$ input concentration on steady-state exopolysaccharide production $(\triangle)$, glucose conversion efficiency $(\mathbf{\Delta}), E_{520}(O)$ and culture viscosity ( $\left.\boldsymbol{\square}\right)$.

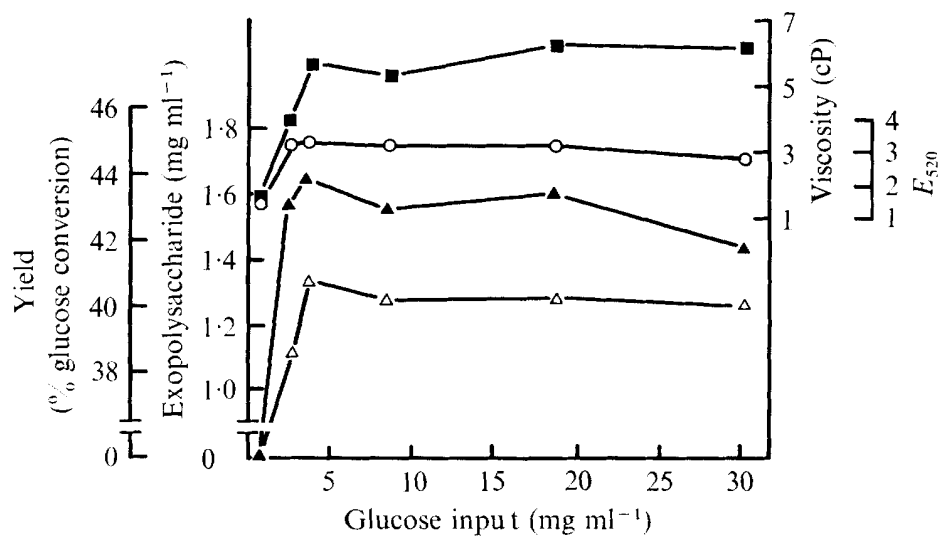

Fig. 7. Effect of glucose input concentration on steady-state exopolysaccharide production $(\triangle)$, glucose conversion efficiency $(\mathbf{\Delta}), E_{520}(O)$ and culture viscosity ( $\left.\boldsymbol{\square}\right)$.

Exopolysaccharide levels of $0 \cdot$ I I and $2 \cdot 2 \mathrm{mg} \mathrm{ml}^{-1}$ were obtained with glucose inputs of $6 \cdot 3$ and $10.5 \mathrm{mg} \mathrm{ml}^{-1}$ respectively (glucose conversion $\mathrm{I} 2 \cdot 9$ and $\mathrm{I} 6.0 \%$ ).

Phosphate. A dilution rate of $0^{\cdot} \mathrm{I}_{4} \mathrm{~h}^{-1}$ was selected to minimize viscosity effects associated with the increased cell population at higher nitrogen input levels. Phosphate limitation did not increase polysaccharide production (Fig. 8). The efficiency of glucose conversion was low because of the higher initial nitrogen content of the medium and the increased dilution rate.

The polysaccharide varied little in overall composition irrespective of the $\mathrm{pH}$, temperature, nitrogen, carbon or phosphate content of the growth medium (Table I). The qualitative monosaccharide composition of complete acid hydrolysates of the exopolysaccharide samples was examined chromatographically and no significant variations were observed. In addition the acyl component of all samples analysed was constant at 9 to $12 \%$. The rheological characteristics of the exopolysaccharide samples were not determined and at the high shear rate used $\left(437 \mathrm{~s}^{-1}\right)$ the apparent viscosity of the culture was related to its exopolymer content. However, variations in the solution properties of xanthan gum have been observed in preparations, formed by variant strains, which have a lower pyruvic acid content (Sandford et al., I977). 


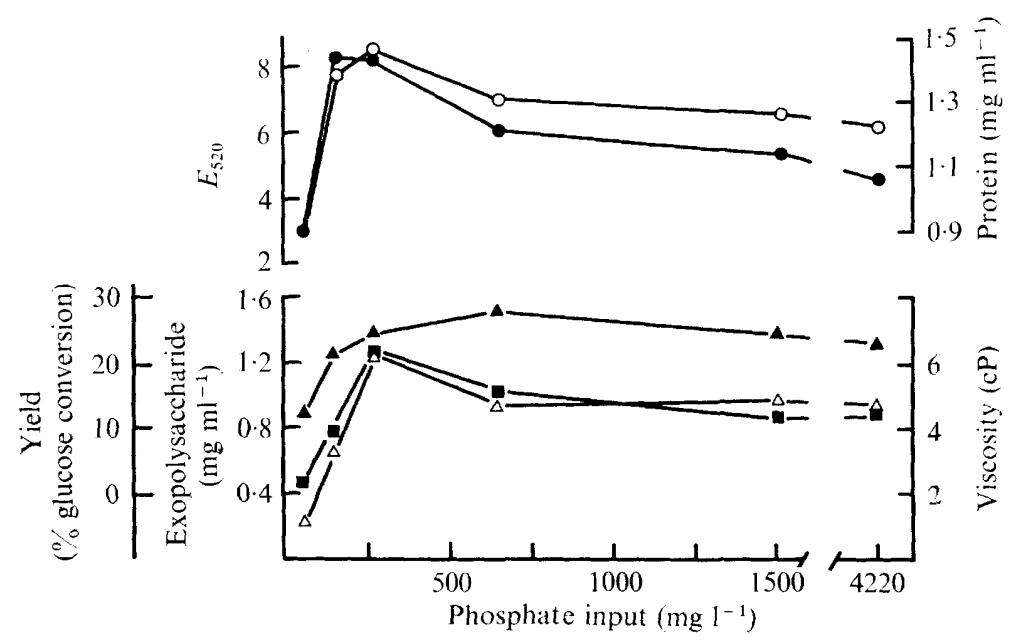

Fig. 8. Effect of phosphate input concentration on steady-state exopolysaccharide production $(\triangle)$, glucose conversion efficiency $(\boldsymbol{\Delta}), E_{520}(O)$, total culture protein $(\boldsymbol{O})$ and culture viscosity $(\mathbf{a})$.

\section{DISCUSSION}

Continuous fermentation studies confirmed that exopolysaccharide production by Pseudomonas NCIBI I 264 was influenced by medium composition, temperature, $\mathrm{pH}$, and the growth rate of the organism. Maximum steady-state levels of polysaccharide were obtained under conditions of nitrogen limitation with excess carbohydrate substrate at $30{ }^{\circ} \mathrm{C}$ and at $\mathrm{pH} 7 \cdot 0$. The efficiency of glucose conversion into exopolysaccharide was as high as $73 \%$ in chemostat cultures, compared with only $30 \%$ in batch culture.

As in batch culture, and in common with other pseudomonads (Goto, Murakawa \& Kuwahara, 1973; Moraine \& Rogovin, 1973), polysaccharide production was favoured by a high carbon: nitrogen ratio in the growth medium. Increasing the concentration of the carbon source when in excess did not enhance the yield of polysaccharide in either batch (Williams \& Wimpenny, 1977) or continuous fermentations. The initial glucose concentration of 2.5 to $3.0 \%(\mathrm{w} / \mathrm{v})$, shown to be optimal for polysaccharide production by Pseudomonas NCIB I 264, Pseudomonas aeruginosa (Goto et al., 1973) and Xanthomonas campestris (Rogovin et al., 196I) when grown in chemically defined media in batch culture, can thus be reduced to 0.5 to $1.0 \%$ for continuous fermentations (cf. Silman \& Rogovin, 1972).

The inclusion of phosphate in defined media has been shown to be necessary for maximum exopolymer formation by Pseudomonas NCIBI I264 (Williams \& Wimpenny r977) and other Pseudomonas strains (Goto et al., 1971, 1973). Similarly in continuous fermentations the steady-state polysaccharide levels, at a controlled optimum $\mathrm{pH}$, were reduced under conditions of phosphate limitation. To obtain maximum exopolymer synthesis it was essential to maintain the $\mathrm{pH}$ at or near to neutrality. Slime production by $P$. aeruginosa (Goto et al., 197I) and the xanthan fermentation (Moraine \& Rogovin, 1973) were similarly optimal at $\mathrm{pH} 7$, the rate of gum production by Xanthomonas campestris in continuous culture being related to culture $\mathrm{pH}$ (Silman \& Rogovin, 1970). The fermentation efficiency may thus be increased by $\mathrm{pH}$ control; Moraine \& Rogovin (I97I) demonstrated that xanthan gum could be more efficiently produced in higher yields by continuously controlling the $\mathrm{pH}$ of the fermentation liquor.

The growth temperature is also critical in determining the extent of exopolysaccharide production. Although the optimum temperature for maximum cell yield of Alcaligenes faecalis var. myxogenes occurred at $32{ }^{\circ} \mathrm{C}$, maximum polysaccharide yields were obtained at $28{ }^{\circ} \mathrm{C}$ (Harada et al., 1965). Similarly the temperature optimum for the xanthan fermentation was at $28^{\circ} \mathrm{C}$ and continued product formation was dependent on this tempera- 
ture being maintained throughout (Moraine \& Rogovin, 1973). Exopolysaccharide formation by Pseudomonas NCIBII264 was, however, maximum at $30^{\circ} \mathrm{C}$ and the culture density was constant over the temperature range 20 to $37.5{ }^{\circ} \mathrm{C}$. Goto et al. (I97I) indicated that the yield of slime formed by $P$. aeruginosa was greater at $37^{\circ} \mathrm{C}$ than at $25{ }^{\circ} \mathrm{C}$ whereas slime production with the strain used by Evans \& Linker (1973) increased with decreasing temperature. Other bacterial strains, including certain Enterobacteriaceae (Wilkinson, Duguid \& Edmunds, I954), produce higher polysaccharide yields at lower temperatures, and mutants of Klebsiella aerogenes have been isolated that exhibit temperature-dependent exopolysaccharide synthesis (Norval \& Sutherland, 1969).

Another factor which is believed to influence exopolysaccharide production is the availability of oxygen, although there are no quantitative data available correlating polysaccharide formation and oxygen tension. The impeller speed and gassing rate were selected so as to maintain efficient aeration in the presence of the exopolysaccharide. Lowering the aeration rate (from 500 to $400 \mathrm{ml} \mathrm{min}^{-1}$ ) had no apparent effect on polysaccharide formation, although the inclusion of baffles led to increased polysaccharide yields in shaken flask cultures over a $48 \mathrm{~h}$ period (Williams, I974). Wash-out from the chemostat occurred if aeration was stopped. Duguid \& Wilkinson (1953) observed that anaerobiosis was specifically unfavourable to exopolysaccharide synthesis by Aerobacter aerogenes, whilst conditions of low aeration favoured growth and polysaccharide production by Rhizobium meliloti (Dudman, I964).

During batch cultures, polysaccharide production did not commence until late in the exponential phase of growth but then continued maximally during the stationary phase when growth had ceased (Williams \& Wimpenny, 1977). The generation time of the organism in defined medium during batch culture was $2.3 \mathrm{~h}$ and as the dilution rate approached $0.3 \mathrm{~h}^{-1}$ exopolysaccharide formation decreased. The characteristics of exopolysaccharide production in batch culture were thus similar to those of a secondary metabolite. Similarly polysaccharide production by Zoogloea ramigera (Parsons \& Dugan, I97I), Zoogloea MP6 (Unz \& Farrah, 1976) and P. fluorescens (Eagon, 1956) occurred in the late exponential and stationary growth phase. During continuous culture secondary metabolites can be produced at low dilution rates where balanced growth is continuously maintained, or through nutrient imbalance. At dilution rates lower than $0.06 \times \mu_{\max }$ all or a part of the population exhibit some properties typical of the non-growing state (Pirt, 1972), and although dilution rates were thus in excess of this critical growth rate, exopolysaccharide production continued. Polysaccharide levels were highest at lower dilution rates, as were the mean residence times of the organism, but decreased with increasing dilution rate, although the cell population remained constant. At the lower dilution rates the higher polysaccharide levels may themselves be growth limiting, as Tanzer et al. (1969) reported that growth restriction of plaque-forming streptococci was associated with dextran formation, whilst Moraine \& Rogovin (1973) proposed that increased fermentation viscosities and encapsulation were factors which contributed to growth limitation by restricting the transport of nutrients into the cell. However, in this series of experiments, fermentation conditions were pre-selected so that, in general, the polysaccharide content, and hence viscosity, of the fermentation liquor was such that efficient aeration of the culture was possible.

The practical aspects of a continuous fermentation to produce microbial exopolysaccharide on a large scale were assessed by Silman \& Rogovin (1970, 1972) who were able to obtain over $80 \%$ conversion of glucose into the exopolymer xanthan gum. Chemostat cultures of Pseudomonas NCIBI 1264 would convert over $70 \%$ of the glucose utilized into exopolysaccharide, compared with $30 \%$ in a $50 \mathrm{~h}$ batch fermentation. However, with further investigation it is possible that the efficiency of the continuous fermentation may be improved or the system modified to increase polysaccharide yields. The use of multi-stage systems for the xanthan fermentation has been suggested (Moraine \& Rogovin, I966; 
Lindblom \& Patton, 1967) and preliminary investigations with non-proliferating suspensions of Pseudomonas NCIBI I264 (Williams, 1974) indicate that exopolymer formation in a two-stage system in which glucose-limited cells are transferred to a nitrogen-free polysaccharide production stage, should be considered as a means of further increasing the fermentation efficiency.

A.G.W. acknowledges the financial support of a C.A.P.S. award from the Science Research Council and Tate \& Lyle Ltd.

\section{REFERENCES}

Cooper, C. M., Fernstrom, G. A. \& Miller, S. A. (I944). Performance of agitated gas-liquid contactors. Industrial and Engineering Chemistry 36, 504-509.

Dubois, M., Gilles, K. A., Hamilton, J. K., Rebers, P. A. \& SMIth, F. (1956). Colorimetric method for the determination of sugars and related substances. Analytical Chemistry 28, 350356.

DudMAN, W. F. (1964). Growth and extracellular polysaccharide production by Rhizobium meliloti in defined medium. Journal of Bacteriology 88, 640-645.

Duguid, J. P. \& Wilkinson, J. F. (1953). The influence of cultural conditions on polysaccharide production by Aerobacter aerogenes. Journal of General Microbiology 9, 174-I89.

EAGON, R. G. (1956). Studies on polysaccharide formation by Pseudomonas fluorescens. Canadian Journal of Microbiology 2, 673-676.

Evans, C. G. T., Herbert, D. \& Tempest, D. W. (1970). The continuous cultivation of microorganisms. II. Construction of a chemostat. Methods in Microbiology 2, 277-328.

Evans, L. R. \& Linker, A. (I973). Production and characterisation of the slime of Pseudomonas aeruginosa. Journal of Bacteriology II6, 915-924.

Fiske, C. H. \& Subbarow, Y. (1925). The colorimetric determination of phosphorus. Journal of Biological Chemistry 66, 375-400.

Goto, S., ENomoto, S., TAKahashi, Y. \& MotoMatsu, R. (1971). Slime production by Pseudomonas aeruginosa. I. Conditions for slime production by the cellophane plate method. Japanese Journal of Microbiology 15, 31 7-324.

Goto, S., Murakawa, T. \& Kuwahara, S. (I973). Slime production by Pseudomonas aeroginosa. II. A new synthetic medium and cultural conditions for slime production by Pseudomonas aeruginosa. Japanese Journal of Microbiology r7, 45-5I.

Harada, T., Yoshimura, T., Hidaka, H. \& KoreedA, A. (1965). Production of a new acidic polysaccharide, succinoglucan, by Alcaligenes faecalis var. myxogenes. Agricultural and Biological Chemistry 29, 757-762.

Lilly, V. G., Wilson, H. A. \& Leach, J. G. (I958). Bacterial polysaccharides. II. Laboratory scale production of polysaccharide by species of Xanthomonas. Applied Microbiology 6, 105-108.

LindBlom, G. P. \& Patton, J. T. (1967). U.S. Patent No. 3, 328, 262.

Lowry, O. H., Rosebrough, N. J., FArR, A. L. \& RANDALL, R. J. (195I). Protein measurement with the Folin phenol reagent. Journal of Biologica Chemistry 193, 265-275.

Moraine, R. A. \& Rogovin, P. (I966). Kinetics of polysaccharide B-I459 fermentation. Biotechnology and Bioengineering 8, $51 \mathrm{I}-524$.

Moraine, R. A. \& Rogovin, P. (197I). Xanthan biopolymer production at increased concentration by $\mathrm{pH}$ control. Biotechnology and Bioengineering I3, 38I-39I.

Moraine, R. A. \& Rogovin, P. (1973). Kinetics of the xanthan fermentation. Biotechnology and Bioengineering $\mathbf{1 5}, 225-237$.

Norval, M. \& SuTHerland, I. W. (I969). A group of Klebsiella mutants showing temperaturedependent polysaccharide synthesis. Journal of General Microbiology 57, 369-377.

Parsons, A. B. \& Dugan, P. R. (I97I). Production of extracellular polysaccharide matrix by Zoogloea ramigera. Applied Microbiology 21, 657-66I.

PIRT, S. J. (I972). Prospects and problems in continuous flow culture of microorganisms. Journal of Applied Chemistry and Biotechnology 22, 5564.

Rogovin, S. P. (1969). U.S. Patent No. 3, 485, 7 I9. Rogovin, S. P., Anderson, R. F. \& Cadmus, R. F. (I96I). Production of polysaccharide with Xanthomonas campestris. Biotechnology and Bioengineering 3, 5I-63.

Sandford, P. A., Pittsley, J. E., Knutson, C. A., Watson, P. R., Cadmus, M. C. \& Jeanes, A. (I977). Variation in Xanthomonas campestris NRRL B. I459: characterisation of xanthan products of differing pyruvic acid content. In Extracellular Microbial Polysaccharides, A.C.S. Symposium Series, vol. 45, pp. 192-210. Edited by P. A. Sandford and A. Laskin. Washington: American Chemical Society.

Srlman, R. W. \& Rogovin, S. P. (1970), Continuous fermentation to produce xanthan biopolymer: laboratory investigation. Biotechnology and Bioengineering 7, 75-83.

Silman, R. W. \& Rogovin, S. P. (I972). Continuous fermentation to produce xanthan biopolymer: effect of dilution rate. Biotechnology and Bioengineering 14, 23-31.

Solorzano, L. (1969). Determination of ammonia in natural waters by the phenol-hypochlorite method. Limnology and Oceanography 14, 799$80 \mathrm{I}$.

TANZER, J. M., WoOd, W. I. \& KrIChevSky, M. I. (1969). Linear growth kinetics of plaque-forming streptococci in the presence of sucrose. Journal of General Microbiology 58, I 25-133. 

UNZ, R.F. \& FARRAH, S. R. (1976). Exopolymer
production and flocculation by Zoogloea MP6. Applied and Environmental Microbiology 31, 623626.

Wilkinson, J. F., Duguid, J. P. \& Edmunds, P. N. (1954). The distribution of polysaccharide production in Aerobacter and Escherichia strains and its relation to antigenic character. Journal of General Microbiology 11, 59-72.

Williams, A. R. (I969). An electromagnetic modification of the Zimm-Crothers viscometer. Journal of Scientific Instruments 2, 279-28I.

WILliams, A. G. (1974). Extracellular polysaccharide production by a Gram-negative bacterial isolate. Ph.D. thesis, University of Wales.
Williams, A. G. \& WimpenNy, J. W. T. (I976). Exopolysaccharide production by Pseudomonas PBI in batch and continuous culture: effect of growth conditions. Journal of Applied Chemistry and Biotechnology 26, 326-327.

Williams, A. G. \& WimpenNy, J. W. T. (I977). Exopolysaccharide production by Pseudomonas NCIBII264 grown in batch culture. Journal of General Microbiology 102, I 3-2I.

Williams, A. G., WimpenNy, J. W. T. \& Lawson, C. J. (1973). The production of an extracellular polysaccharide by a Pseudomonas-type microorganism. Journal of General Microbiology 77, xiii. 